\title{
A National Comparison of Burnout and Work-Life Balance Among Internal Medicine Hospitalists and Outpatient General Internists
}

\author{
Daniel L. Roberts, MD*, Tait D. Shanafelt, MD², Liselotte N. Dyrbye, MD, MHPE³ , Colin P. West, MD, PhD ${ }^{4,5}$
}

\begin{abstract}
${ }^{1}$ Division of Hospital Internal Medicine, Department of Medicine, Mayo Clinic, Phoenix, Arizona; ${ }^{2}$ Division of Hematology, Department of Medicine, Mayo Clinic, Rochester, Minnesota; ${ }^{3}$ Division of Primary Care Internal Medicine, Department of Medicine, Mayo Clinic, Rochester, Minnesota; ${ }^{4}$ Division of General Internal Medicine, Department of Medicine, Mayo Clinic, Rochester, Minnesota; ${ }^{5}$ Division of Biomedical Statistics and Informatics, Department of Health Sciences Research, Mayo Clinic, Rochester, Minnesota.
\end{abstract}

BACKGROUND: General internists suffer higher rates of burnout and lower satisfaction with work-life balance than most specialties, but the impact of inpatient vs outpatient practice location is unclear.

METHODS: Physicians in the American Medical Association Physician Masterfile were previously surveyed about burnout, depression, suicidal ideation, quality of life, fatigue, work-life balance, career plans, and health behaviors. We extracted and compared data for these variables for the 130 internal medicine hospitalists and 448 outpatient general internists who participated. Analyses were adjusted for age, sex, hours worked, and practice setting.

RESULTS: There were $52.3 \%$ of the hospitalists and $54.5 \%$ of the outpatient internists affected by burnout $(P=0.86)$. High scores on the emotional exhaustion subscale $(43.8 \%$ vs $48.1 \%, P=0.71)$ and on the depersonalization subscale (42.3\% vs $32.7 \%, P=0.17$ ) were common but similar in fre- quency in the 2 groups. Hospitalists were more likely to score low on the personal accomplishment subscale (20.3\% vs $9.6 \%, P=0.04)$. There were no differences in symptoms of depression (40.3\% for hospitalists vs $40.0 \%$ for outpatient internists, $P=0.73$ ) or recent suicidality $(9.2 \%$ vs $5.8 \%, P=0.15)$. Rates of reported recent work-home conflict were similar (48.4\% vs $41.3 \%, P=0.64)$, but hospitalists were more likely to agree that their work schedule leaves enough time for their personal life and family $(50.0 \%$ vs $42.0 \%, P=0.007$ ).

CONCLUSIONS: Burnout was common among both hospitalists and outpatient general internists, although hospitalists were more satisfied with work-life balance. A better understanding of the causes of distress and identification of solutions for all internists is needed. Journal of Hospital Medicine 2014;9:176-181. (C) 2014 Society of Hospital Medicine
An increasingly robust body of literature has identified burnout as a substantial problem for physicians across specialties and practice settings. ${ }^{1-4}$ Burnout, a workrelated condition characterized by emotional exhaustion, depersonalization, and lack of a sense of personal accomplishment, ${ }^{5}$ has been tied to negative consequences for patients, physicians, and the medical profession including medical errors, ${ }^{6}$ poor physician health, ${ }^{7,8}$ and decreased professionalism. ${ }^{9}$ Studies of burnout among general internists have pointed to time pressures, lack of work control, and difficult patient encounters as possible contributors. ${ }^{10,11}$

Burnout has been demonstrated to affect a sizable proportion of hospitalists, with prevalence estimates from prior studies varying from $12.9 \%$ to $27.2 \%$, although nearly all studies of US hospitalists have relied on single-item instruments. ${ }^{12-15}$ Hospital-based physicians have represented a rapidly expanding segment of the internist workforce for more than a decade, ${ }^{14}$ but studies of the impact of inpatient vs

*Address for correspondence and reprint requests: Daniel Roberts, MD, 5777 East Mayo Boulevard, Phoenix, AZ 85054; Telephone: 480342-1387; Fax: 480-342-1388; E-mail: roberts.daniel@mayo.edu

Received: September 1, 2013; Revised: November 15, 2013; Accepted: December 13, 2013

2014 Society of Hospital Medicine DOI 10.1002/jhm.2146

Published online in Wiley Online Library (Wileyonlinelibrary.com). outpatient practice location on burnout and career satisfaction are limited. A meta-analysis of the impact of practice location on burnout relied almost exclusively on noncomparative studies from outside the United States. ${ }^{15}$ A recent study of US physician burnout and satisfaction with work-life balance showed that general internists expressed below average satisfaction with work-life balance and had the second highest rate of burnout among 24 specialties. ${ }^{4}$ However, this report did not differentiate between general internists working in inpatient vs outpatient settings.

We therefore examined burnout, satisfaction with work-life balance, and other aspects of well-being among internal medicine hospitalists relative to outpatient general internists, using a national sample developed in partnership with the American Medical Association.

\section{METHODS}

\section{Physician Sample}

As described previously, ${ }^{4}$ the American Medical Association Physician Masterfile, a nearly complete record of US physicians, was used to generate a sample of physicians inclusive of all specialty disciplines. The 27,276 physicians who opened at least 1 invitation email were considered to have received the invitation to participate in the study. Participation was voluntary, and all responses were anonymous. For this 
analysis, internal medicine hospitalists were compared with general internists reporting primarily outpatient practices. The physician sample provided information on demographics (age, sex, and relationship status) and on characteristics of their practice. Burnout, symptoms of depression, suicidal ideation in the past 12 months, quality of life (QOL), satisfaction with work-life balance, and certain health behaviors were evaluated as detailed below.

\section{Burnout}

Burnout among physicians was measured using the Maslach Burnout Inventory (MBI), a validated 22item questionnaire considered the gold standard tool for measuring burnout. ${ }^{5,16}$ The MBI has subscales to evaluate each domain of burnout: emotional exhaustion, depersonalization, and low personal accomplishment. Because other burnout studies have focused on the presence of high levels of emotional exhaustion or depersonalization as the foundation of burnout in physicians, ${ }^{17-19}$ we considered physicians with a high score on the depersonalization or emotional exhaustion subscales to have at least 1 manifestation of professional burnout.

\section{Symptoms of Depression and Suicidal Ideation}

Symptoms of depression were assessed using the 2-item Primary Care Evaluation of Mental Disorders, ${ }^{20}$ a standardized and validated assessment for depression screening that performs as well as longer instruments. ${ }^{21}$ Recent suicidal ideation was evaluated by asking participants, "During the past 12 months, have you had thoughts of taking your own life?" This item was designed to measure somewhat recent, but not necessarily active, suicidal ideation. These questions have been used extensively in other studies. ${ }^{22-25}$

\section{Quality of Life and Fatigue}

Overall QOL and mental, physical, and emotional QOL were measured by a single-item linear analog scale assessment. This instrument measured QOL on a 0 ("as bad as it can be") to 10 ("as good as it can be") scale validated across a wide range of medical conditions and populations. ${ }^{26-28}$ Fatigue was measured using a similar standardized linear analog scale assessment question, for which respondents indicated their level of fatigue during the past week. ${ }^{29}$ The impact of fatigue on daily activities such as driving was also evaluated.

\section{Satisfaction With Work-Life Balance and Career Plans}

Satisfaction with work-life balance was assessed by the item, "My work schedule leaves me enough time for my personal/family life," with response options "strongly agree," “agree," "neutral," "disagree," or "strongly disagree." Individuals who indicated "strongly agree" or "agree" were considered to be satisfied with their work-life balance, whereas those who indicated "strongly disagree" or "disagree" were considered to be dissatisfied with their work-life balance. Experience of work-home conflicts was assessed as in prior research. ${ }^{4}$ Participants were also asked about plans to change jobs or careers.

\section{Health Behaviors}

A limited set of health and wellness behaviors was addressed in the survey to provide insight into other aspects of physician well-being. These included whether respondents had a primary care provider and questions concerning routine screening and alcohol and substance use. Alcohol use was assessed using the Alcohol Use Disorders Identification Test, version C (AUDIT-C). ${ }^{30}$ An AUDIT-C score of at least 4 for men and at least 3 for women indicates alcohol misuse, and a score of at least 5 for men and at least 4 for women indicates alcohol abuse and possible dependence. ${ }^{30}$

\section{Statistical Analysis}

Standard descriptive summary statistics were used to characterize the physician samples. Associations between variables were evaluated using the Kruskal-Wallis test (for continuous variables) or $\chi^{2}$ test (for categorical variables). All tests were 2-sided, with a type I error level of 0.05 . Multivariate analysis of differences between hospitalists and outpatient general internists was performed using multiple linear or logistic regression for continuous or categorical data, respectively. Covariates in these models included age, sex, weekly work hours, and practice setting. All of the analyses were performed using SAS version 9.2 (SAS Institute, Inc., Cary, NC).

\section{RESULTS}

In the full survey across all specialties, 7288 physicians $(26.7 \%)$ provided survey responses. ${ }^{4}$ There were 448 outpatient internists and 130 internal medicine hospitalists who agreed to participate. Demographically, hospitalists were younger, worked longer hours, and were less likely to work in private practice than outpatient general internists (Table 1).

\section{Distress and Well-Being Variables}

High levels of emotional exhaustion affected $43.8 \%$ of hospitalists and $48.1 \%$ of outpatient general internists (odds ratio [OR]: $0.91,95 \%$ confidence interval [CI]: 0.56-1.48), and high levels of depersonalization affected $42.3 \%$ of hospitalists and $32.7 \%$ of outpatient general internists (OR: 1.42, 95\% CI: 0.86$2.35)$. Overall burnout affected $52.3 \%$ of hospitalists and $54.5 \%$ of outpatient general internists (OR: 0.96, 95\% CI: $0.58-1.57)$. None of these factors differed statistically in multivariate models adjusted for factors known to be associated with burnout, including sex, age, weekly work hours, and practice setting $(P=0.71,0.17$, and 0.86 , respectively; Table 2$)$. However, low levels of personal accomplishment were reported by $20.3 \%$ of hospitalists and $9.6 \%$ of 


\begin{tabular}{|c|c|c|c|}
\hline Characteristic & $\begin{array}{l}\text { Hospitalists } \\
(n=130)\end{array}$ & $\begin{array}{l}\text { Outpatient General } \\
\text { Internists }(n=448)\end{array}$ & $P$ \\
\hline Sex, $n(\%)$ & & & 0.56 \\
\hline Male & $86(66.2 \%)$ & $284(63.4 \%)$ & \\
\hline Female & $44(33.8 \%)$ & $164(36.6 \%)$ & \\
\hline Age, mean (SD) & $46.9(12.4)$ & 53.6 (10.2) & $<0.001$ \\
\hline Median & 45.0 & 55.0 & \\
\hline $\begin{array}{l}\text { Years in practice, mean (SD) } \\
\text { Median }\end{array}$ & $\begin{array}{c}14.0(12.0) \\
10.0\end{array}$ & $\begin{array}{c}21.6(10.7) \\
22.0\end{array}$ & $<0.001$ \\
\hline $\begin{array}{l}\text { Hours worked per week, mean (SD) } \\
\text { Median }\end{array}$ & $\begin{array}{c}55.0(18.1) \\
50.0\end{array}$ & $\begin{array}{c}50.0(15.1) \\
50.0\end{array}$ & 0.04 \\
\hline Practice setting, $n(\%)$ & & & $<0.001$ \\
\hline Private practice/hospital & $36(31.0 \%)$ & $303(69.2 \%)$ & \\
\hline Academic medical center & $37(31.9 \%)$ & $41(9.4 \%)$ & \\
\hline $\begin{array}{l}\text { Other (including veterans hospital } \\
\text { and active military practice) }\end{array}$ & $43(37.1 \%)$ & $94(21.5 \%)$ & \\
\hline
\end{tabular}

NOTE: Abbreviations: SD, standard deviation.

TABLE 2. Distress and Well-Being Results for Internal Medicine Hospitalists vs Outpatient General Internists

\begin{tabular}{|c|c|c|c|}
\hline Variable & $\begin{array}{l}\text { Hospitalists } \\
(n=130)\end{array}$ & $\begin{array}{l}\text { Outpatient General } \\
\text { Internists }(n=448)\end{array}$ & $P^{*}$ \\
\hline \multicolumn{4}{|l|}{ Burnout } \\
\hline Emotional exhaustion high ( $\geq 27)$ & $57 / 130(43.8 \%)$ & 215/447 (48.1\%) & 0.71 \\
\hline Mean (SD) & $24.7(12.5)$ & $25.4(14.0)$ & \\
\hline Median & 24.9 & 26.0 & \\
\hline Depersonalization high $(\geq 10)$ & $55 / 130(42.3 \%)$ & $146 / 447(32.7 \%)$ & 0.17 \\
\hline Mean (SD) & $9.1(6.9)$ & $7.5(6.3)$ & \\
\hline Median & 7.0 & 6.0 & \\
\hline Personal accomplishment low $(\leq 33)$ & $26 / 128(20.3 \%)$ & $43 / 446(9.6 \%)$ & 0.04 \\
\hline Mean (SD) & $39.0(7.6)$ & $41.4(6.0)$ & \\
\hline Median & 41.0 & 43.0 & \\
\hline High burnout (EE $\geq 27$ or $D P \geq 10$ ) & $68 / 130(52.3 \%)$ & $244 / 448(54.5 \%)$ & 0.86 \\
\hline \multicolumn{4}{|l|}{ Depression } \\
\hline Depression screen + & $52 / 129(40.3 \%)$ & $176 / 440(40.0 \%)$ & 0.73 \\
\hline Suicidal thoughts in past 12 months & $12 / 130(9.2 \%)$ & $26 / 445(5.8 \%)$ & 0.15 \\
\hline \multicolumn{4}{|l|}{ Quality of life } \\
\hline Overall mean (SD) & $7.3(2.0)$ & $7.4(1.8)$ & 0.85 \\
\hline Median & 8.0 & 8.0 & \\
\hline $\operatorname{Low}(<6)$ & $21 / 130(16.2 \%)$ & $73 / 448(16.3 \%)$ & \\
\hline Mental mean (SD) & $7.2(2.1)$ & $7.3(2.0)$ & 0.89 \\
\hline Median & 8.0 & 8.0 & \\
\hline $\operatorname{Low}(<6)$ & $23 / 130(17.7 \%)$ & $92 / 448(20.5 \%)$ & \\
\hline Physical mean (SD) & $6.7(2.3)$ & $6.9(2.1)$ & 0.45 \\
\hline Median & 7.0 & 7.0 & \\
\hline $\operatorname{Low}(<6)$ & $35 / 130(26.9 \%)$ & $106 / 448(23.7 \%)$ & \\
\hline Emotional mean (SD) & $7.0(2.3)$ & $6.9(2.2)$ & 0.37 \\
\hline Median & 7.0 & 7.0 & \\
\hline $\operatorname{Low}(<6)$ & $30 / 130(23.1 \%)$ & $114 / 448(25.4 \%)$ & \\
\hline \multicolumn{4}{|l|}{ Fatigue } \\
\hline Mean (SD) & $5.8(2.4)$ & $5.9(2.4)$ & 0.57 \\
\hline Median & 6.0 & 6.0 & \\
\hline $\begin{array}{l}\text { Fallen asleep while driving (among } \\
\text { regular drivers only) }\end{array}$ & $11 / 126(8.7 \%)$ & $19 / 438(4.3 \%)$ & 0.23 \\
\hline
\end{tabular}

NOTE: Abbreviations: DP, depersonalization; $\mathrm{EE}$, emotional exhaustion; SD, standard deviation. *Adjusted for age, sex, weekly work hours, and practice setting.
TABLE 3. Work-Life Balance and Career Variables for Internal Medicine Hospitalists vs Outpatient General Internists

\begin{tabular}{|c|c|c|c|}
\hline Variable & $\begin{array}{l}\text { Hospitalists } \\
(n=130)\end{array}$ & $\begin{array}{l}\text { Outpatient General } \\
\text { Internists }(n=448)\end{array}$ & $P^{*}$ \\
\hline Work-home conflict in last 3 weeks & $62 / 128(48.4 \%)$ & $183 / 443(41.3 \%)$ & 0.64 \\
\hline $\begin{array}{l}\text { Work-home conflict resolved in } \\
\text { favor of: }\end{array}$ & & & 0.79 \\
\hline Work & $37 / 118(31.4 \%)$ & $131 / 405(32.2 \%)$ & \\
\hline Home & $15 / 118(12.7 \%)$ & $43 / 405(10.6 \%)$ & \\
\hline Meeting both needs & $66 / 118(55.9 \%)$ & $231 / 405(57.0 \%)$ & \\
\hline $\begin{array}{l}\text { Work schedule leaves enough time } \\
\text { for personal life/family }\end{array}$ & & & 0.007 \\
\hline Strongly agree & $20(15.4 \%)$ & $70(15.7 \%)$ & \\
\hline Agree & $45(34.6 \%)$ & $117(26.3 \%)$ & \\
\hline Neutral & $21(16.2 \%)$ & $66(14.8 \%)$ & \\
\hline Disagree & $27(20.8 \%)$ & $119(26.7 \%)$ & \\
\hline Strongly disagree & $17(13.1 \%)$ & $73(16.4 \%)$ & \\
\hline Missing & 0 & 3 & \\
\hline Likelihood of leaving current practice & & & 0.002 \\
\hline Definite & $17(13.1 \%)$ & $34(7.6 \%)$ & \\
\hline Likely & $21(16.2 \%)$ & $53(11.9 \%)$ & \\
\hline Moderate & $21(16.2 \%)$ & $67(15.0 \%)$ & \\
\hline Slight & $38(29.2 \%)$ & $128(28.7 \%)$ & \\
\hline None & $33(25.4 \%)$ & $164(36.8 \%)$ & \\
\hline Missing & 0 & 2 & \\
\hline Would choose to become physician again & $81 / 130(62.3 \%)$ & $306 / 441(69.4 \%)$ & 0.86 \\
\hline
\end{tabular}

*NOTE: Adjusted for age, sex, weekly work hours, and practice setting.

outpatient general internists (OR: 1.93, 95\% CI: $1.02-3.65, P=0.04)$.

Approximately $40 \%$ of physicians in both groups screened positive for depression (OR: $0.92,95 \%$ CI: $0.56-1.51, P=0.73)$. In addition, $9.2 \%$ of hospitalists reported suicidal ideation in the last 12 months compared to $5.8 \%$ of outpatient internists (OR: 1.86, 95\% CI: 0.80-4.33, $P=0.15$ ) (Table 2).

Overall QOL and QOL in mental, physical, and emotional domains were nearly identical in the 2 groups (Table 2). Fatigue was also similar for hospitalists and outpatient general internists, and $8.5 \%$ of hospitalists reported falling asleep in traffic while driving compared to $4.2 \%$ of outpatient internists (OR: 1.76, 95\% CI: $0.70-4.44, P=0.23$ ).

\section{Work-Life Balance and Career Variables}

Experience of recent work-home conflicts was similar for hospitalists and outpatient general internists (Table 3). However, hospitalists were more likely to agree or strongly agree that their work schedule leaves enough time for their personal life and family $(50.0 \%$ vs $42.0 \%$, OR: $2.06,95 \%$ CI: $1.22-3.47, P=0.007)$.

Hospitalists were more likely to express interest in leaving their current practice in the next 2 years, with $13.1 \%$ vs $7.6 \%$ reporting "definite" plans to leave and $29.2 \%$ vs $19.5 \%$ reporting at least "likely" plans to leave (OR: 2.31, 95\% CI: $1.35-3.97, P=0.002$ ). Among those reporting a likely or definite plan to leave, hospitalists were more likely to plan to look for 
a different practice and continue to work as a physician $(63.2 \%$ vs $39.1 \%)$, whereas outpatient general internists were more likely to plan to leave medical practice $(51.9 \%$ vs $22.0 \%, P=0.004)$. Hospitalists with plans to reduce their work hours were more likely than their outpatient colleagues to express an interest in administrative and leadership roles $(19.4 \%$ vs $12.1 \%)$ or research and educational roles $(9.7 \%$ vs $4.0 \%, P=0.05)$.

\section{Health Behavior Variables}

Hospitalists were less likely to report having a primary care provider in the adjusted analyses $(55.0 \%$ vs $70.3 \%$, OR: $0.49,95 \%$ CI: $0.29-0.83, P=0.008$ ). Use of illicit substances was uncommon in both groups $(94.6 \%$ of hospitalists and $96.0 \%$ of outpatient general internists reported never using an illicit substance (OR: $0.87,95 \% \mathrm{CI}: 0.31-2.49, P=0.80$ ). Symptoms of alcohol abuse were similar between the 2 groups $(11.7 \%$ and $13.3 \%$, respectively, OR: 0.64 , $95 \%$ CI: $0.30-1.35, P=0.24)$, but symptoms of alcohol misuse were more common among outpatient general internists $(34.2 \%$ vs $21.9 \%$, OR: $1.75,95 \%$ CI: $1.01-3.03, P=0.047)$.

\section{DISCUSSION}

The primary result of this national study applying well-validated metrics is that the overall rates of burnout among hospitalists and outpatient general internal medicine physicians were similar, as were rates of positive depression screening and QOL. Although these groups did not differ, the absolute rates of distress found in this study were high. Prior research has suggested that possible explanations for these high rates of distress include excessive workload, loss of workassociated control and meaning, and difficulties with work-home balance. ${ }^{4}$ The present study, in the context of prior work showing that general internists have higher rates of burnout than almost any other specialty, suggests that the front-line nature of the work of both hospitalists and outpatient general internists may exacerbate these previously cited factors. These results suggest that efforts to address physician well-being are critically needed for both inpatient and outpatient physicians.

Despite the noted similarities, differences between hospitalists and outpatient general internists in certain aspects of well-being merit further attention. For example, the lower rate of personal accomplishment among hospitalists relative to outpatient generalists is consistent with prior evidence. ${ }^{15}$ The reasons for this difference are unknown, but the relative youth and inexperience of the hospitalists may be a factor. US hospitalists have been noted to "feel like glorified residents" in at least 1 report, ${ }^{31}$ a factor that might also negatively impact personal accomplishment.

It is also worthwhile to place the burnout results for both groups in context with prior studies.
Although we found high rates of burnout among outpatient physicians, our outpatient sample's mean MBI subset scores are not higher than previous samples of American $^{32}$ and Canadian ${ }^{33}$ outpatient physicians, suggesting that this finding is neither new nor artifactual. Placing the hospitalist sample in perspective is more difficult, as very few studies have administered the MBI to US hospitalists, and those that have either administered 1 component only to an exclusive academic sample ${ }^{34}$ or administered it to a small mixture of hospitalists and intensivists. ${ }^{35}$ The prevalence of burnout we report for our hospitalist sample is higher than that reported by studies that utilized single-item survey items ${ }^{12-14}$; it is likely that the higher prevalence we report relates more to a more detailed assessment of the components of burnout than to a temporal trend, although this cannot be determined definitively from the data available.

The finding that $9.2 \%$ of hospitalists and $5.8 \%$ of outpatient general internists reported suicidal thoughts in the past 12 months is alarming, though consistent with prior data on US surgeons. ${ }^{35}$ Although the higher rate of suicidal thoughts among hospitalists was not statistically significant, a better understanding of the factors associated with physician suicidality should be the focus of additional research.

Hospitalists were more likely than outpatient internists to report plans to leave their current practice in this study, although their plans after leaving differed. The fact that they were more likely to report plans to find a different role in medicine (rather than to leave medicine entirely or retire) is likely a function of age and career stage. The finding that hospitalists with an interest in changing jobs were more likely than their outpatient colleagues to consider administrative, leadership, education, and research roles may partially reflect the greater number of hospitalists at academic medical centers in this study, but suggests that hospitalists may indeed benefit from the availability of opportunities that have been touted as part of hospitalist "diastole." 36

Finally, rates of alcohol misuse and abuse found in this study were consistent with those reported in prior studies. ${ }^{37-39}$ These rates support ongoing efforts to address alcohol-related issues among physicians. In addition, the proportion of outpatient general internists and hospitalists reporting having a primary care provider was similar to that seen in prior research. ${ }^{40}$ The fact that 1 in 3 physicians in this study did not have a primary care provider suggests there is great room for improvement in access to and prioritization of healthcare for physicians in general. However, it is noteworthy that hospitalists were less likely than outpatient general internists to have a primary care provider even after adjusting for their younger age as a group. The reasons behind this discrepancy are unclear but worthy of further investigation. 
Several limitations of our study should be considered. The response rate for the entire study sample was $26.7 \%$, which is similar to other US national physician surveys in this topic area. ${ }^{41-43}$ Demographic comparisons with national data suggest the respondents were reasonably representative of physicians nationally, ${ }^{4}$ and all analyses were adjusted for recognized demographic factors affecting our outcomes of interest. We found no statistically significant differences in demographics of early responders compared with late responders (a standard approach to evaluate for response bias), ${ }^{14,31}$ further supporting that responders were representative of US physicians. Despite this, response bias remains possible. For example, it is unclear if burned out physicians might be more likely to respond (eg, due to the personal relevance of the survey topic) or less likely to respond (eg, due to being too overwhelmed to open or complete the survey).

A related limitation is the relatively small number of hospitalists included in this sample, which limits the power of the study to detect differences between the study groups. The hospitalists in this study were also relatively experienced, with a median of 10 years in practice, although the overall demographics match closely to a recent national survey of hospitalists. Although age was considered in the analyses, this study may not fully characterize burnout patterns among very junior or very senior hospitalists. In addition, although analyses were adjusted for observed differences between the study groups for a number of covariates, there may be differences between the study groups in other, unmeasured factors that could act as confounders of the observed results. For example, the allocation of each individual's time to different activities (eg, clinical, research, education, administration), workplace flexibility and control, and meaning may all contribute to distress and well-being, and could not be assessed in this study.

In conclusion, the degree of burnout, depression, and suicidal ideation in both hospitalists and outpatient general internists is similar and substantial. Urgent attention directed at better understanding the causes of distress and identifying solutions for all internists is needed.

\section{Acknowledgements}

The authors acknowledge the role of the American Medical Association in completing this study.

Disclosures: The views expressed in this article are those of the authors and do not represent the views of, and should not be attributed to, the American Medical Association. The authors report no conflicts of interest.

\section{References}

1. Olkinuora M, Asp S, Juntunen J, Kauttu K, Strid L, Aarimaa M. Stress symptoms, burnout and suicidal thoughts in Finnish physicians. Soc Psychiatry Psychiatr Epidemiol. 1990;25:81-86.

2. Linzer M, Visser MR, Oort FJ, Smets EM, McMurray JE, de Haes HC; Society of General Internal Medicine (SGIM) Career Satisfaction Study Group (CSSG). Predicting and preventing physician burnout: results from the United States and the Netherlands. Am J Med. 2001; 111:170-175.
3. Bressi C, Porcellana M, Gambini O, et al. Burnout among psychiatrists in Milan: a multicenter study. Psychiatr Serv. 2009;60:985-988.

4. Shanafelt TD, Boone S, Tan L, et al. Burnout and satisfaction with work-life balance among US physicians relative to the general US population. Arch Intern Med. 2012;172:1377-1385.

5. Maslach C, Jackson SE. The measurement of experienced burnout. J Occup Behav. 1981;2:99-113.

6. Shanafelt TD, Balch CM, Bechamps G, et al. Burnout and medical errors among American surgeons. Ann Surg. 2010;251:995-1000.

7. Wallace JE, Lemaire JB, Ghali WA. Physician wellness: a missing quality indicator. Lancet. 2009;374:1714-1721.

8. Taylor C, Graham J, Potts HW, Richards MA, Ramirez AJ. Changes in mental health of UK hospital consultants since the mid-1990s. Lancet. 2005;366:742-744.

9. Dyrbye LN, Massie FS Jr, Eacker A, et al. Relationship between burnout and professional conduct and attitudes among US medical students. JAMA. 2010;304:1173-1180.

10. Linzer M, Baler Manwell L, Williams ES, et al.; MEMO (Minimizing Error, Maximizing Outcomes) Investigators. Working conditions in primary care: physician reactions and care quality. Ann Intern Med. 2009;151:28-36.

11. An PG, Rabatin JS, Manwell LB, Linzer M, Brown RL, Schwartz MD; MEMO Investigators. Burden of difficult encounters in primary care: data from the Minimizing Error, Maximizing Outcomes study. Arch Intern Med. 2009;169:410-414.

12. Hoff TH, Whitcomb WF, Williams K, Nelson JR, Cheesman RA. Characteristics and work experiences of hospitalists in the United States. Arch Intern Med. 2001;161(6):851-858.

13. Glasheen JJ, Misky GJ, Reid MB, Harrison RA, Sharpe B, Auerbach A. Career satisfaction and burnout in academic hospital medicine. Arch Intern Med. 2011;25:171(8):782-785.

14. Hinami K, Whelan CT, Miller JA, Wolosin RJ, Wetterneck TB; Society of Hospital Medicine Career Satisfaction Task Force. Job characteristics, satisfaction, and burnout across hospitalist practice models. J Hosp Med. 2012;7:402-410.

15. Roberts DL, Cannon KC, Wellik KE, Wu Q, Budavari AI. Burnout in inpatient-based vs outpatient-based physicians: a systematic review and meta-analysis. J Hosp Med. 2013;8:653-664.

16. Maslach C, Jackson S, Leiter M. Maslach Burnout Inventory Manual. 3rd ed. Palo Alto, CA: Consulting Psychologists Press; 1996.

17. Thomas NK. Resident burnout. JAMA. 2004;292(23):2880-2889.

18. Shanafelt TD, Bradley KA, Wipf JE, Back AL. Burnout and selfreported patient care in an internal medicine residency program. Ann Intern Med. 2002;136:358-367.

19. Rosen IM, Gimotty PA, Shea JA, Bellini LM. Evolution of sleep quantity, sleep deprivation, mood disturbances, empathy, and burnout among interns. Acad Med. 2006;81:82-85.

20. Spitzer RL, Williams JB, Kroenke K, et al. Utility of a new procedure for diagnosing mental disorders in primary care: the PRIME-MD 1000 study. JAMA. 1994;272:1749-1756.

21. Whooley MA, Avins AL, Miranda J, Browner WS. Case-finding instruments for depression: two questions are as good as many. J Gen Intern Med. 1997;12:439-445.

22. Meehan PJ, Lamb JA, Saltzman LE, O'Carroll PW. Attempted suicide among young adults: progress toward a meaningful estimate of prevalence. Am J Psychiatry. 1992;149:41-44.

23. Kessler RC, Borges G, Walters EE. Prevalence of and risk factors for lifetime suicide attempts in the National Comorbidity Survey. Arch Gen Psychiatry. 1999;56:617-626.

24. Kessler RC, Berglund P, Borges G, Nock M, Wang PS. Trends in suicide ideation, plans, gestures, and attempts in the United States, 1990-1992 to 2001-2003. JAMA. 2005;293:2487-2495.

25. Cooper-Patrick L, Crum RM, Ford DE. Identifying suicidal ideation in general medical patients. JAMA. 1994;272:1757-1762.

26. Gudex C, Dolan P, Kind P, Williams A. Health state valuations from the general public using the visual analogue scale. Qual Life Res. $1996 ; 5: 521-531$

27. Shanafelt TD, Novotny P, Johnson ME, et al. The well-being and personal wellness promotion strategies of medical oncologists in the North Central Cancer Treatment Group. Oncology. 2005;68:23-32.

28. Rummans TA, Clark MM, Sloan JA, et al. Impacting quality of life for patients with advanced cancer with a structured multidisciplinary intervention: a randomized controlled trial. J Clin Oncol. 2006;24: 635-642.

29. West CP, Tan AD, Habermann TM, Sloan JA, Shanafelt TD. Association of resident fatigue and distress with perceived medical errors. JAMA. 2009;302:294-300.

30. Bush K, Kivlahan DR, McDonell MB, Fihn SD, Bradley KA. The AUDIT alcohol consumption questions (AUDIT-C): an effective brief screening test for problem drinking. Arch Intern Med. 1998;158: 1789-1795.

31. Hinami K, Whelan CT, Wolosin RJ, Miller JA, Wetterneck TB. Worklife and satisfaction of hospitalists: toward flourishing careers. J Gen Intern Med. 2012;27(1):28-36.

32. Krasner MS, Epstein RM, Beckman H, et al. Association of an educational program in mindful communication with burnout, empathy, 
and attitudes among primary care physicians. JAMA. 2009;302(12): 1284-1293.

33. Lee FJ, Stewart M, Brown JB. Stress, burnout, and strategies for reducing them: what's the situation among Canadian family physicians? Can Fam Physician. 2008;54(2):234-235.

34. Lucas B, Trick W, Evans A, et al. Emotional exhaustion, life stress, and perceived control among medicine ward attending physicians: a randomized trial of 2 - versus 4 -week ward rotations [abstract]. J Hosp Med. 2011;6(4 suppl 2):S43-S44.

35. Shanafelt TD, Balch CM, Dyrbye L, et al. Special report: suicidal ideation among American surgeons. Arch Surg. 2011;146:54-62.

36. Arora V, Fang MC, Kripalani S, Amin AN. Preparing for "diastole": advanced training opportunities for academic hospitalists. J Hosp Med. 2006;1:368-377.

37. Hughes PH, Brandenburg N, Baldwin DC Jr, et al. Prevalence of substance use among US physicians. JAMA. 1992;267:23332339 .
38. Bazargan M, Makar M, Bazargan-Hejazi S, Ani C, Wolf KE. Preventive, lifestyle, and personal health behaviors among physicians. Acad Psychiatry. 2009;33:289-295.

39. Oreskovich MR, Kaups KL, Balch CM, et al. Prevalence of alcohol use disorders among American surgeons. Arch Surg. 2012;147:168-174.

40. Gross CP, Mead LA, Ford DE, Klag MJ. Physician, heal thyself? Regular source of care and use of preventive health services among physicians. Arch Intern Med. 2000;160:3209-3214.

41. Allegra CJ, Hall R, Yothers G. Prevalence of burnout in the U.S. oncologic community: results of a 2003 survey. J Oncol Pract. 2005;1(4): $140-147$.

42. Kuerer HM, Eberlein TJ, Pollock RE, et al. Career satisfaction, practice patterns and burnout among surgical oncologists: report on the quality of life of members of the Society of Surgical Oncology. Ann Surg Oncol. 2007;14:3042-3053.

43. Shanafelt TD, Balch CM, Bechamps G, et al. Burnout and career satisfaction among American surgeons. Ann Surg. 2009;250(3):463-471. 